\title{
Unerupted maxillary anterior supernumerary tooth - A surgical intervention
}

Santosh M. Sholapurmath ${ }^{1}$, Sneha B. Bharuka ${ }^{2}$, Bosky J asani ${ }^{3}$

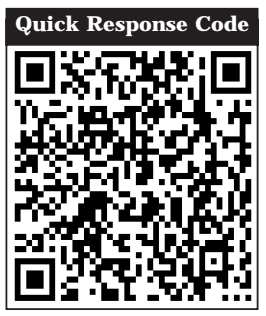

doi: $10.5866 / 2014.621578$

${ }^{1}$ Associate professor,

${ }^{2}$ Post Graduate Student.

Department of Pedodontics and Preventive dentistry, Maratha Mandal's Nathajirao G Halgekar Institute of Dental Sciences and Research Centre,

Belgaum.

\section{Article Info:}

Received: J anuary 10, 2014

Review Completed: February 11, 2014

Accepted: March 11, 2014

Available Online: J uly, 2014 (www.nacd.in)

(c) NAD, 2014 - All rights reserved

Email for correspondence:

dr.sbbharuka@gmail.com

\begin{abstract}
:
Supernumerary tooth is one that is additional to the normal series and can be found in almost any region of the dental arch. Mesiodens is one of the most common types of supernumerary tooth found in the premaxilla between two central incisors. Here is a case report which represents a case of impacted mesiodens in a 9 year old child patient. Surgical removal of the mesiodens was indicated, owing to the impaction and deviation of the permanent central incisors caused by the impacted supernumerary tooth.
\end{abstract}

Key words: Mesiodens, surgical removal, supernumerary tooth.

\section{INTRODCTION:}

Supernumerary tooth is one that is additional to the normal series and can be found in almost any region of the dental arch. ${ }^{1}$ Supernumerary teeth can be single or multiple, occurring unilaterally or bilaterally in both the jaws, accompanied by a syndrome.

They can be classified on the basis of location and morphology (Flow chart 1 and 2). Prevalence of supernumerary teeth in permanent dentition is about $0.1-3.6 \%$, whereas in deciduous dentition it is lower; $0.3-0.8 \%$. Its prevalence is equally distributed in the deciduous dentition, whereas more prevalent in males in permanent dentition. About $15-34 \%$ of permanent dentition supernumerary teeth erupt, while only $2 / 3^{\text {rd }}$ of them erupt in deciduous dentition. ${ }^{1}$

Delayed eruption of permanent maxillary incisors has numerous causes such as supernumerary teeth, tooth malformation or dilacerations, tooth agenesis, cysts or other pathological obstructions in the eruptive path, retained primary incisor that has become ankylosed, presence of a dense mucoperiosteum or submucosa 
that acts as a physical barrier to eruption, lack of space or in association with certain syndromes. However, the most common cause cited for the delayed eruption of permanent maxillary incisors is the presence of supernumerary teeth in the premaxillary region. ${ }^{2}$

I mpacted maxillary supernumerary teeth in the anterior region are an interesting clinical entity. They possess unique diagnostic and management concerns for clinicians. I mpacted maxillary anterior supernumerary teeth and their follicles delay the normal eruption of permanent teeth and displace them; thus it is important to detect them early and to plan an appropriate treatment for them.

I mpacted maxillary anterior supernumerary teeth have many etiologic factors, out of which three theories are most prevalent. They are atavism, dichotomy and dental Iamina hyperactivity.

- Atavism theory states that hyperdontia was the result of phylogenetic reversion to extinct primates with three pairs of incisors.

- The dichotomy is the theory that fission in the tooth bud resulted into hyperdontia. Two supplemental forms would result on equal, complete division, whereas, one normal tooth and one smaller form would result on unequal division.

- The hyperactivity theory states that hyperdontia results from independent, locally conditioned hyperactivity of the dental lamina. According to this theory, the supernumerary tooth originates from a lingual extension of a tooth bud.

- Heredity or genetics can also play a role in the development of supernumeraries, as they are more common in relatives of affected individuals than in the general population. ${ }^{1}$

Most current literature supports the dental Iamina hyperactivity theory. ${ }^{2}$

Mesiodens a term coined by Bolk, is a supernumerary teeth present in the midline of maxilla between two central incisors. ${ }^{3}$ Overall prevalence of the mesiodens is about $0.15-1.9 \%{ }^{4}$ The complications due to supernumerary teeth include failure of eruption of permanent incisors, crowding or midline diastema, axial rotation or displacement of erupted permanent incisors, resorption of adjacent teeth, root anomaly, eruption into the nasal cavity and cyst formation. ${ }^{5}$ Here, we present a case report of a supernumerary tooth in theanterior maxillary region - an impacted inverted mesiodens causing delayed eruption of permanent maxillary central incisors.

\section{CASE REPORT}

A 9-year-old girl reported to the Department of Pedodontics and Preventive dentistry, Maratha Mandal's Nathajirao G. Hal gekar I nstitute of Dental Sciences and Research Centre, Belgaum, with the chief complaint of non-eruption of upper front permanent tooth. The parents expressed their concerns about the eruption failure of their child's anterior tooth. The patient's medical history was insignificant and with no familial history of supernumerary or congenitally missing teeth.

However, the parents gavea past dental history of trauma 6 - 7 years back. \#61 was fractured as a result of the trauma, and was extracted by a dentist at that time. On intraoral examination 51, 52 and 62 were found to be retained and 61 was missing (Figure 1). Also, pit and fissure caries were present with 55, 65, 75, 36 and 46, and smooth surface caries were present with 84 . The patient had a Class I mixed dentition occlusion.

Periapical and occlusal radiographs revealed the presence of a supernumerary tooth, located between the roots of the permanent central incisors, which was inverted and lying palatally, obstructing the eruption of 21 and also deflecting the eruption path of 11 (Figure 2). The need for removal of the supernumerary tooth was explained to the patient and parents, to facilitate eruption of permanent central incisors.

\section{SURGICAL PROCEDURE:}

Local anesthesia was administered via labial and palatal infiltration. Using a \#15 blade, incision was made and a full thickness flap was reflected with the help of a periosteal elevator. A slight el evation was evident on the palate near the midline. This was determined to be the position of the mesiodens with palpation. Bone overlying the mesiodens was removed while taking care not to remove or damage the adjacent permanent teeth. The mesiodens was then luxated with an elevator. 


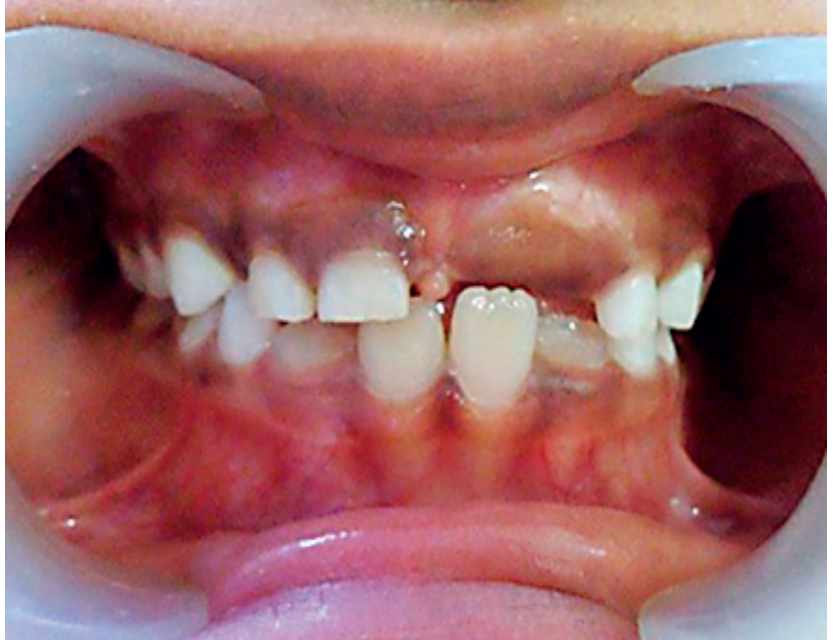

Figure 1: Pre-operative intraoral view showing missing 61.

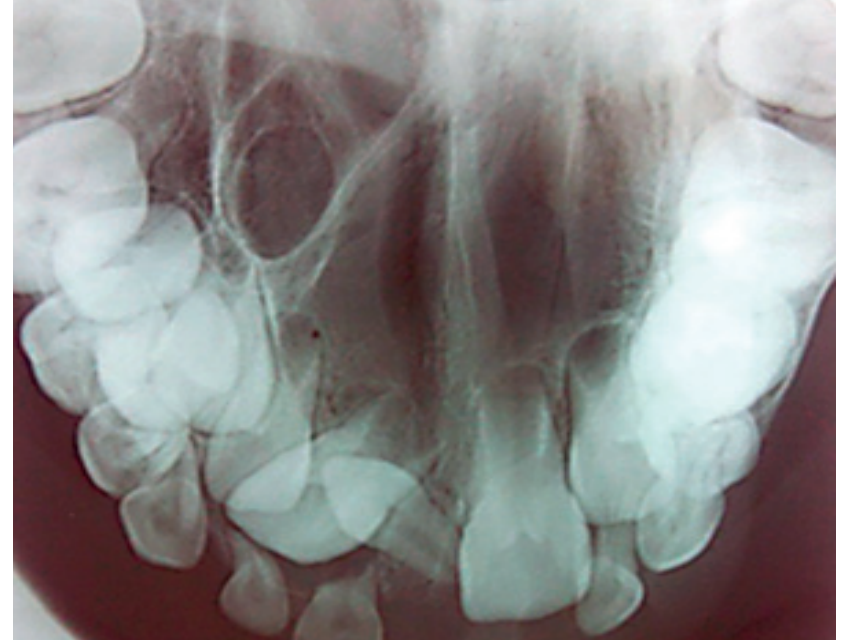

Figure 2: Occlusal radiograph showing inverted palatally placed mesiodens.

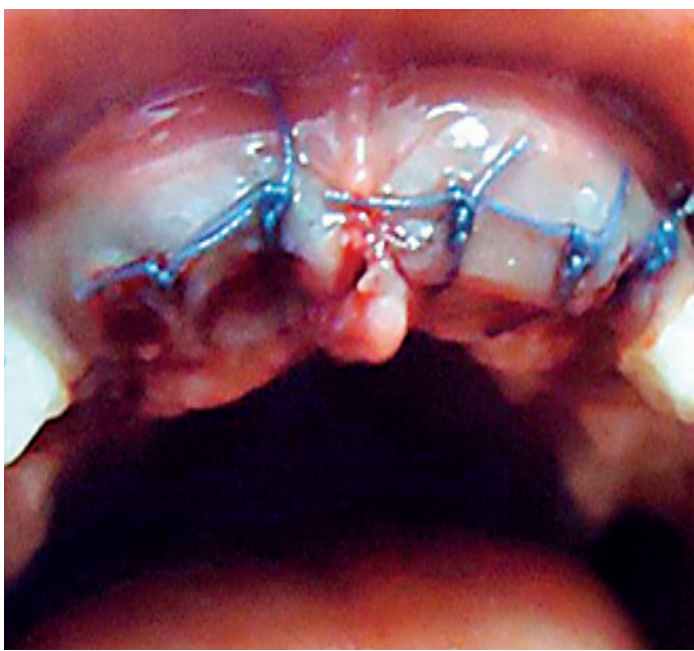

Figure 3: Post- surgical intraoral view showing extracted 51, 52 and 62.

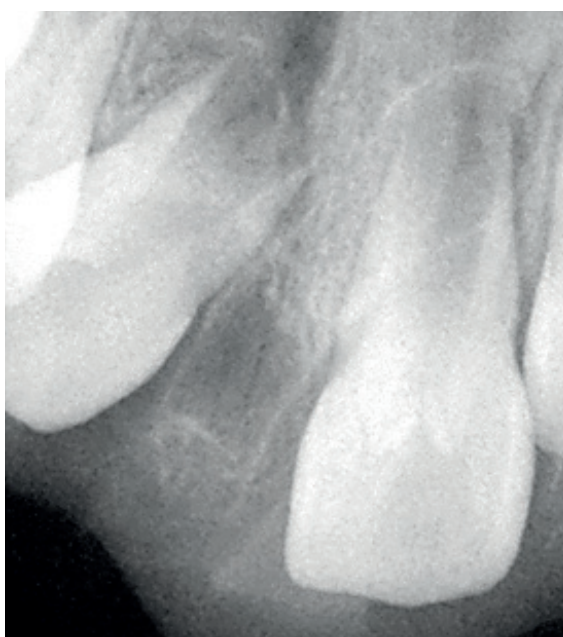

Figure 6: 15 days post-operative IOPA showing 11, 21

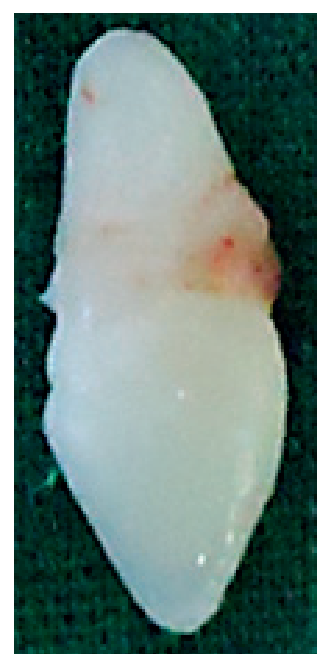

Figure 4: Surgically removed conical mesiodens.

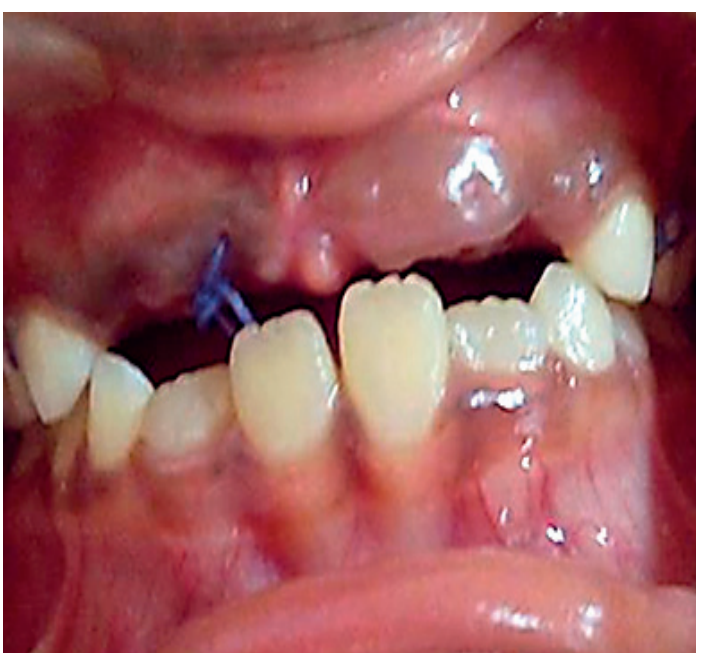

Figure 5: 15 days post operative view showing erupting 21 .

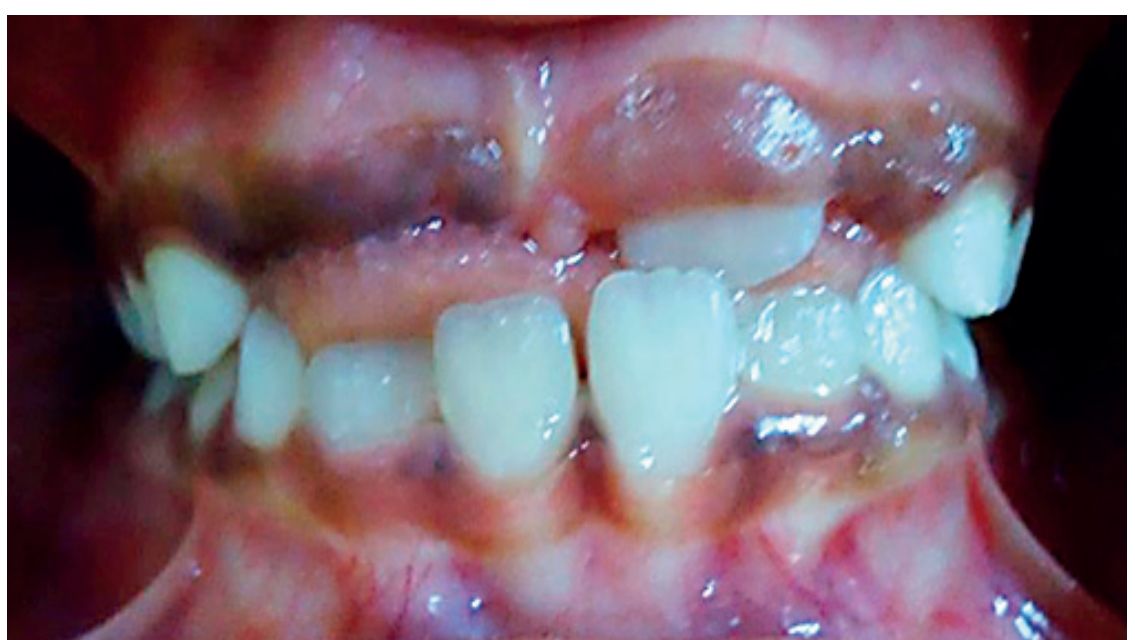

Figure 7: 1 month post - operative view showing erupting 21. 


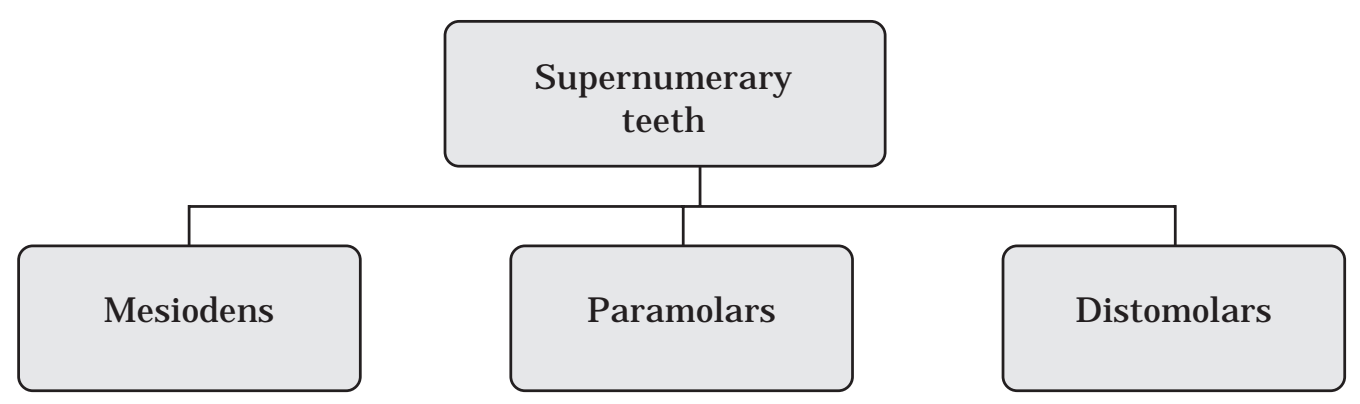

Flow chart 1: Classification of supernumerary teeth on basis of location.

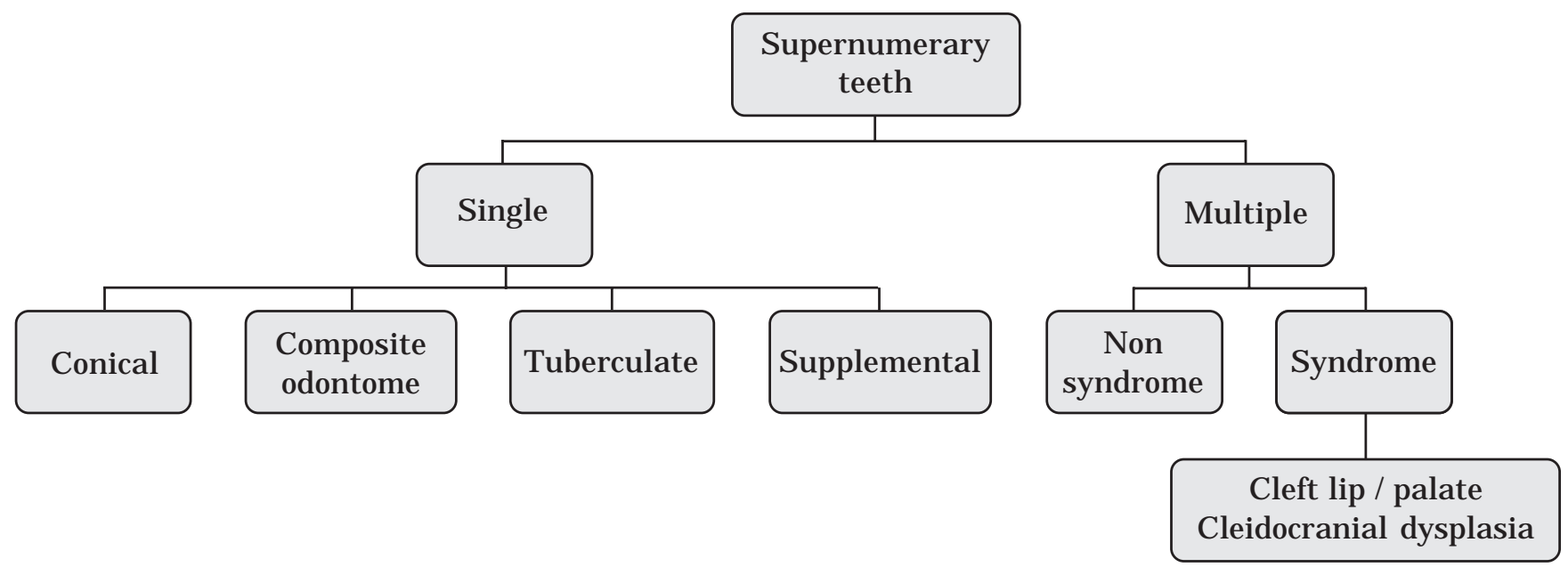

Flow chart 2: Classification of supernumerary teeth on basis of morphology.

The retained primary teeth 51, 52 and 62 were also extracted at the same appointment to aid in eruption of permanent teeth. The extraction site was irrigated with betadine and saline, and the wound closed with interrupted sutures given using resorbable vicryl suture material (Figure 3 and 4). The patient's recovery was uneventful with no unsual signs or symptoms and was scheduled for bimonthly recalls.

Removal of the inverted mesiodens had aided in the eruption of central incisor. After 2 weeks, the left central incisor (21) was seen erupting into the oral cavity (Figure 5 and 6). Clinical examination after 1 month follow - up revealed 21 erupting in a crossbite with respect to 31 (figure 7). The patient is regularly reviewed and appropriate orthodontic care will be subsequently provided after eruption of central incisors.

\section{DISCUSSION}

Diagnosis of a mesiodens is best achieved by thorough clinical and radiographic examination. Parallax radiographic technique can be used to determine the buccolingual position of unerupted supernumerary teeth along with maxillary occlusal radiography. Once a diagnosis of supernumerary tooth is made, the clinician must decide on treatment to minimize further sequel. ${ }^{2}$

Management of supernumerary tooth depends on type and position of tooth. Their immediate removal is indicated in cases with inhibition or delay of eruption of permanent incisors, if they interfere with orthodontic appliances, displacement of adjacent teeth or a presence of associated pathological condition. ${ }^{5}$ Munns has stated that, early removal of a mesiodens results into better prognosis. $^{6}$ 
Extraction of the supernumerary teeth is a general rule to avoid complications. There are two alternatives for the timing of surgical removal of a supernumerary tooth: ${ }^{7}$

- The first option is removal of the supernumerary tooth as soon as it is diagnosed. However, this could create dental phobia problems for a young child and has been said to cause devitalization or deformation of adjacent teeth.

- Second option is to leave the supernumerary until completion of root development of the adjacent teeth. The potential disadvantages associated with this deferred plan are; loss of eruptive force of adjacent teeth, loss of space and crowding of the affected arch, and possible midline shifts.

According to Solares, extraction during the early mixed dentition stage allows normal eruptive forces to promote spontaneous eruption of the permanent central incisors following extraction. ${ }^{8} \mathrm{H}$ ogstrom and Andersson suggested that early interventions are preferable to take advantage of the spontaneous eruption potential of the permanent incisors and to prevent anterior space loss and midline deviation. ${ }^{7}$

Management of the delayed eruption of a tooth due to a supernumerary can be approached by any one of the following three methods: ${ }^{9}$

- First, by conservative management, involving removal of the supernumerary only.

- Second, by removal of the supernumerary tooth together with the bone overlying the unerupted tooth with or without placement of a bonded attachment for orthodontic traction and replacement of the flap (closed exposure).

- And third, by removal of the supernumerary and exposure of the unerupted tooth, with or without placement of a bonded attachment for orthodontic traction (open exposure).

In the present case, surgical removal of the mesiodens was judged necessary, since it had caused deviation of the central incisors and was also preventing their eruption.

The treatment of an impacted mesiodens can be delayed until the maturation of the apex of the unerupted central incisor. ${ }^{10} \mathrm{H}$ owever, this delay could either result in delayed eruption or malalignment of the erupted incisors. Unfortunately, by the time treatment is carried out, the forces which cause normal eruption of the incisors are diminished. Surgical exposure and subsequent orthodontic treatment are more frequently required in such situations. Also, space loss and a midline shift of the central incisors may have already occurred by this age, due to the eruption and mesial drift of the lateral incisors into the central space. Thus, a significant delay in treatment can create the need for more complex surgical and orthodontic management. ${ }^{2}$

\section{CONCLUSION:}

Mesiodens as the most prevalent form of supernumerary teeth is not a rare condition. Early diagnosis and appropriate management can minimize the potential complications caused by supernumerary tooth. Whatever the etiology is, it is the duty of the practitioner to recognize the signs suggesting the presence of supernumerary tooth. Extraction in mixed dentition helps spontaneous alignment of the adjacent tooth.

\section{REFERENCES:}

1. J indal R, Sharma S, Gupta K. Clinical and surgical considerations for impacted mesiodens in young children. An update. Indian J Oral Sci 2012; 3(2):94-98.

2. Manuja N, Nagpal R, Singh M, Choudhary S. Management of delayed eruption of permanent maxillary incisor associated with the presence of supernumerary teeth: a case report. Int J Clin Pediatr Dent 2011; 4(3):255-259.

3. Bolk L. Supernumerary teeth in the molar region in man. Dent Cosmos 1914; 56:154-167.

4. Primosch RE. Anterior supernumerary teeth-assessment and surgical intervention in children. Pediatr Dent 1981; 3:204-215.

5. Meighani G, Pakdaman A. Diagnosis and management of supernumerary (Mesiodens): A review of literature. J Dent (Tehran) 2010; 7(1):41-49.

6. Munns D. Unerupted incisors. Br J Orthod 1981; 8(1):3942.

7. Hogstrum A, Andersson L. Complications related to surgical removal of anterior supernumerary teeth in children.J Dent Child 1987; 54:341-343.

8. Solares R. The complications of late diagnosis of anterior supernumerary teeth: A case report. ASDC J Dent Child 1990; 57:209-211.

9. Mitchell L, Bennett TG. Supernumerary teeth causing delayed eruption: A retrospective study. Br J Orthod 1992; 19:41-46.

10. Henry RJ , Post AC. A labially positioned mesiodens: Case report. Pediatr Dent 1989; 11:59-63. 